\title{
WELCOMING CHILDREN, PETS AND GUESTS: TOWARDS FUNCTIONAL EQUIVALENCE IN THE LANGUAGES OF 'AGRITURISMO' AND 'FARMHOUSE HOLIDAYS' ${ }^{1}$
}

\author{
Elena Tognini Bonelli \& Elena Manca*
}

\begin{abstract}
This paper takes a contextual and functional view of translation equivalence; it aims to define a 'wider' notion of equivalence built on a network of collocates rather than on single items. Thus, given an initial 'node' $N$ in L1, the identification of a translation equivalent in L2 will proceed through several stages of contextualisation relating each item to its environment and identifying its collocational profile both in L1 and in L2. Furthermore, it will be shown that systematic enlargement of the unit of meaning in terms of patterns of co-occurrence helps to define a typology of the extra-linguistic features associated with it.
\end{abstract}

KEYWORDS: translation, contrastive linguistics, corpus linguistics, language of tourism.

RESUMO: Este artigo assume uma visão contextual e funcional da equivalência tradutória e pretende definir uma noção mais 'abrangente' de equivalência, com base numa rede de colocados e não de palavras isoladas. Assim, dado um 'nódulo' inicial $N$ na L1, a identificação de um equivalente tradutório na L2 passará por diversos estágios de contextualização, relacionando cada item a seu contexto e identifi-

Lecce University, Italy.

1 A first version of the work reported here was presented at the A.I.A. conference in Catania in September 2001 (published in Textus XV, n. 2, 2002). This version, presented at ICAME 2002 (Göteborg) greatly benefited from the careful and stimulating comments of the editors of this volume, Karin Aijmer and Bengt Atenberg, as well as the discussion and the questions that followed the presentation.

TradTerm, 10, 2004, p. 295-312 
cando o perfil colocacional tanto na L1 quanto na L2. Além disso, demonstraremos que a extensão sistemática da unidade de significado em termos de padrões de co-ocorrência ajuda a definir uma tipologia dos traços extralingüisticos a ele associados.

UNITERMOS: tradução; lingüística contrastiva; lingüistica de corpus; linguagem de turismo.

\section{Introduction}

This paper aims to interpret the concept of translation equivalence in terms of linguistic shifts between two different socio-cultural contexts. We start from the assumption that the process of translation has to be seen primarily as a statement of meaning and that to translate means (1) to identify a specific function together with its formal realisations in L1, (2) to compare it with another set (function + formal realisation), or other sets, in L2 and finally, in the light of the previous stage, (3) to attempt to encode the given function into a chosen formal realisation in the target language. Whereas the first two steps can be seen as linguistic and descriptive - it is in fact a matter of comparing formal linguistic features across languages - the third step is strategic, and it involves the input of a translator, his/her awareness of the extra-linguistic features, such as the ultimate purpose of the translation, and his/her ability to negotiate a chosen meaning across languages (Tognini Bonelli, 1996a).

This paper will only consider the first two steps in translation and will concentrate on identifying a chosen function by describing its formal realisations in English, on the one hand, and comparing it with the way that particular meaning is encoded in Italian, on the other. We shall consider in what way the formal realisations of that meaning may differ and whether they are indeed comparable across the two languages. We shall try to demonstrate that these differences and/or correspondences can be revealing of cultural and typological facets and that these have to be reckoned with in the process of translation.

TradTerm, 10, 2004, p. 295-312 


\section{The corpora}

Our data is derived from a set of two comparable corpora (Teubert, 1996) in English and Italian in the fields of 'Agriturismo' in Italy and 'Farmhouse Holidays' in the UK Perhaps the easiest way to characterise the common denominator between these two fields is to say that they offer their customers a relaxing holiday in the countryside and with it a number of country activities related to life on the farm. So, guests are often invited to engage in walking, hiking, riding, fishing, birdwatching, swimming etc. and are encouraged to enjoy the proximity and contact with farm animals. One can expect a comparable typology of services offered and of the ways this offer is put across, provided, of course, allowances are made for differences due to geographical location, national habits and preferences and, in general, the specific requirements of the two different markets. In spite of these differences, ${ }^{2}$ we assume that certain more general concepts will have a fairly straightforward equivalent in terms of their linguistic realisations.

We will henceforth refer to our two corpora as the 'Agriturist' corpus in Italian and the 'Farmhols' corpus in English. We have assembled these corpora from web pages and the Agriturist corpus now stands provisionally at 115.000 words while the Farmhols corpus stands at 203.000 words. They can be considered comparable in that the language they represent has a similar function and aims to sell a similar product.

With this in mind, we consulted, as a first step, the frequency list for the Farmhols corpus and identified the word welcome as a particularly frequent one (Table 1). A series of interviews with the owners of different www pages for farmhouse holidays confirmed the centrality of the word which repeatedly appeared in definitions such as this one:

A Farmhouse holiday can mean different things. It depends on the accommodation etc. The one thing they should all

2 See for instance the importance of 'genuine food' and the pleasures linked to a traditional country cuisine which is central in the Agriturist offer in Italy and has no real equivalent in the Farmhols Corpus.

TradTerm, 10, 2004, p. 295-312 
have in common is a warm and friendly welcome and the peace and beauty of the countryside. (...) Other holidays are like what we provide, self-catering, with the farmer welcoming you to wander on his farm if you wish and also to buy good local food. (...) People coming here always comment on the peace and beauty and the warmth of the welcome. (J. Rider, 2000, personal communication)

Having chosen the word welcome, we faced the first difficulty in identifying a straightforward equivalence pair. We posited as a prima-facie translation equivalent in Italian the word benvenuto, which exists both as an adjective and as an exclamation, ${ }^{3}$ but this word had no comparable frequency in the Agriturist corpus, as shown in Table 1:

\begin{tabular}{|c|c|}
\hline 'FARMHOLS' & 'AGRITURIST' \\
CORPUS & CORPUS \\
\hline Welcome & Benvenuto/ $a / i / e$ \\
324 instances & 4 instances \\
\hline
\end{tabular}

Table 1: Node-to-Node, Frequencies

The difference was so marked that we had to question our initial assumption about the centrality of welcome for both fields, facing therefore the problem of non-equivalence.

In this context, non-equivalence goes beyond the absence of a match between L1 and L2. Sometimes, when we compare across languages, we recognise non-equivalence by the mismatch of a certain word. Take for instance the English word hangover, which needs to be paraphrased in Italian for lack of a direct equivalent. A justification for this phenomenon can be attempted in cultural terms. In our case, the mismatch happens when a word like welcome, which is prominent in terms of frequency in L1, appears only very rarely in L2. The problem we have to consider

3 The word welcome, as well as an adjective and an exclamation, is also used as a verb (see Manca, 2001). In this study we will only consider in some detail the adjectival function.

TradTerm, 10, 2004, p. 295-312 
is, therefore, how to identify an equivalent function given that this may be realised in different ways at the formal level. The other possibility is that for some reason, be it cultural or ideological, the word might not find a direct equivalent.

In order to decide whether indeed the concept of 'welcoming' is so dramatically absent in the Italian of Agriturismo or whether it is simply expressed differently, we adopted an alternative approach: we chose to address the issue of translating a word by starting from the context in which it is most frequently embedded. Our assumptions and our methodology are explained in the sections that follow.

\section{Translating context and function}

The view we take is that equivalence should not, and often cannot, be established at simple word level; when a certain type of equivalence actually exists, this should be established at the wider level of 'functionally-complete units of meaning' (Tognini Bonelli, 1996a/b, 2001). Our aim here is to show how a systematic contextual and co-textual analysis of the data can help the translator to identify this 'wider' notion of equivalence built on a network of collocates rather than on single items. This broadening of the issue is especially necessary when we face the problem of non-equivalence at word level outlined above. However, we also recommend it as a more generally applicable method because it places the analyst in a privileged position for observing and reconciling the contextual patterning and the overall function of the translation unit.

Our method takes us, therefore, to the questioning of the traditional distinction between item and environment, in favour of a model of meaning and translating that ascribes central importance to the phenomenon of co-selection and that sees context as an integral part of the text. Co-selection has been widely discussed in relation to meaning and lexicography (see Sinclair, 1987, 1991 and later) and the results of such discussions, as well asTognini Bonelli's statements, presented below, can now be taken more or less for granted:

TradTerm, 10, 2004, p. 295-312 
- Many textual meanings arise from the co-selection of more than one word.

- Habitual co-selection tends to specialise the function of one or more of the words concerned.

- Co-selection is largely covert and subliminal, which increases its importance in communication (Tognini Bonelli, 2001: 128).

The importance of contextual information for identifying meanings across languages is elaborated by Sinclair and his associates in a collection of papers on corpus-to-corpus translation equivalence (Sinclair et al. eds., 1996). In his preface to that work, Sinclair states that in many cases, when there is no translation equivalent for a chosen word, 'translation can only be achieved by first of all combining the word with one or more others; the whole phrase will then equate with a word or phrase in the other language' (Sinclair, 1996: 175). He proposes:

A system of describing the shared meanings of languages in terms of the actual verbal contexts in which each instance is found. The attraction of the description is the way in which each instance is assumed to be carrying in its immediate environment sufficient differential information to indicate which of several possible meanings is the relevant one, and in the case of translation, what is the appropriate phraseology. (Sinclair, 1996: 174)

This paper aims to take this work on co-selection (see also Francis, 1993; Partington, 1996) one step further and considers the implications of its centrality in translation with particular attention to methodology.

In the process of establishing equivalence, we will also observe how a systematic enlargement of the unit of meaning in terms of patterns of co-occurrence can help to define a typology of the extra-linguistic features associated with it: the type of product offered and also the specific ways in which it is offered. We will examine differences which are not only due to the different geographical provenance of the text but also to cultural diversity.

TradTerm, 10, 2004, p. 295-312 


\section{Methodology}

Our initial word in L1 is welcome - which, for lack of space, will be discussed here only in its adjectival function. The choice of this word is supported by the fact that the word welcome is very prominent in the Farmhols Corpus. A simple word-frequency list reveals immediately that welcome is almost top of the list of lexical words. However, as we mentioned, there is no direct equivalent to it in the Agriturist corpus - this in spite of the existence of a prima-facie equivalent such as benvenuto. Tables 2 and 3 illustrate the frequencies of welcome in the two corpora.

\begin{tabular}{|c|c|c|c|}
\hline \multicolumn{4}{|c|}{ WELCOME (324 instances) } \\
\hline Adjective & Exclamation & Noun & Verb \\
\hline 147 & 104 & 57 & 15 \\
$(46 \%)$ & $(32 \%)$ & $(17 \%)$ & $(5 \%)$ \\
\hline
\end{tabular}

Table 2: Frequencies of welcome in the Farmhols Corpus

\begin{tabular}{|c|c|}
\hline \multicolumn{2}{|c|}{$B E N V E N U T O / a /$ e (4 instances) } \\
\hline Adjective (benvenuti) & Exclamation (benvenuti) \\
\hline 1 & 3 \\
\hline
\end{tabular}

Table 3: Frequencies of benvenuto in the Agriturist Corpus

The mismatch between the frequencies is very clear and, because of this, we shall try to identify a translation equivalent in L2, going through several stages of contextualisation and relating each item to its environment. We shall identify the collocational profile of each item both in L1 and in L2 and establish the possible correspondences between larger units. So, at first, by analysing the concordance to the initial node, we shall locate the node's most frequent collocates. For each of the collocates we shall posit a prima-facie translation equivalent $\left(\mathrm{TE}^{1}, \mathrm{TE}^{2}, \mathrm{TE}^{3}\right.$, etc.). Each of these will be investigated in its own right as a node in the Agriturist Corpus and we shall try to locate an equivalent to welcome within their collocational range. Our methodological steps are outlined in Table 4.

TradTerm, 10, 2004, p. 295-312 


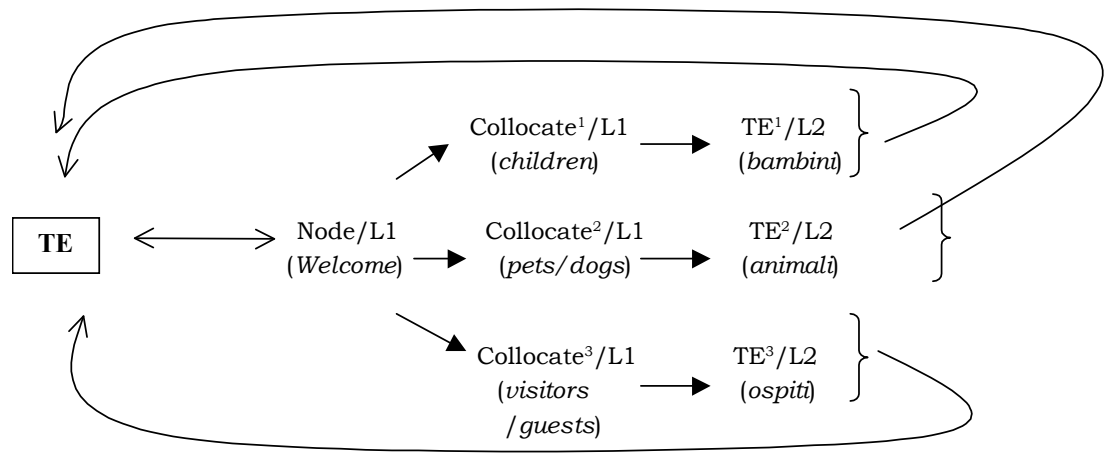

Table 4: Methodological steps for identifying translation equivalence

Starting therefore with bambini, animali and ospiti as the node, we shall consider what type of collocational patterning is associated with each of these terms. Our aim here is to locate, within their collocational range, the patterns belonging to, or denoting, the same semantic field as 'welcome' or, alternatively, to verify their absence.

\subsection{Children and bambini}

The first step in contextualisation will consider the word welcome as a unit taken together with its most frequent collocate: children. A quick examination of the concordance shows two points quite clearly (a few citations are reported in Table 5): firstly, the close association between children and pets or dogs; ${ }^{4}$ secondly, that when children do not share this association with pets, there is always some kind of restriction or limitation to their presence in the farm, be it some age restriction (over 10 .., over 5 ..) or e.g. the fact that no discount is available.

4 We have insufficient data to discuss this in detail, but it certainly should be noted because it seems rather unusual to find them in the same category. * University of Bari, Italy.

TradTerm, 10, 2004, p. 295-312 


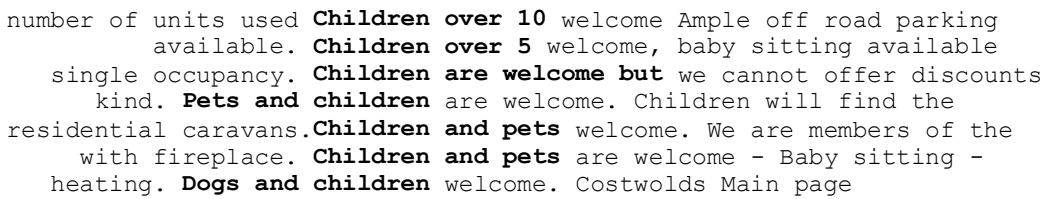

Table 5: children + welcome

The specific age restriction is confirmed by other citations in the same corpus where the noun children is not combined with the adjectival use of welcome, as shown in Table 6.

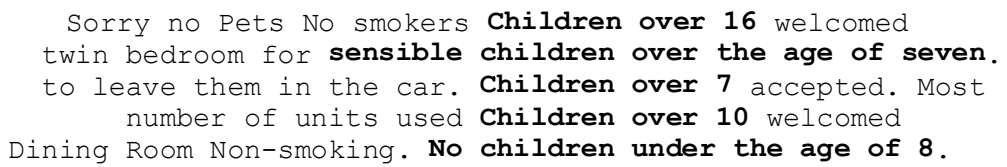

Table 6: children + age limitations

We should remember that this type of 'holiday on the farm' in the UK is often centred on domestic animals and their young and part of the fun offered is to observe them in their own farm environment. The type of conditioned welcome that we see in the instances above, rather than qualifying a warm and friendly reception, seems to function as damage limitation when a facethreatening situation, such as a restriction on the offer, arises. It also reflects well the situational and cultural context in Britain, where children are not always welcomed even in places such as farmhouses, where the presence of farm animals and pets would seem to be an incentive for their presence.

In three instances we find children associated with discount offers, but these are fairly rare $(2.9 \%)$, if compared - as we shall see in Table 7 - with the Agriturist corpus:

there are always good reductions for children. Leave the highways and We have reduced rates for children sharing with their parents per night with discounts for children. In addition, we also

Table 7: children + discounts $(2.9 \%)$

TRADTERM, 10, 2004, p. 295-312 
Let us now proceed to the second step in contextualisation, consisting in the examination of the patterns of co-selection associated with our prima-facie translation equivalent of children (bambini), in the Agriturist Corpus. Table 8 gives some examples.

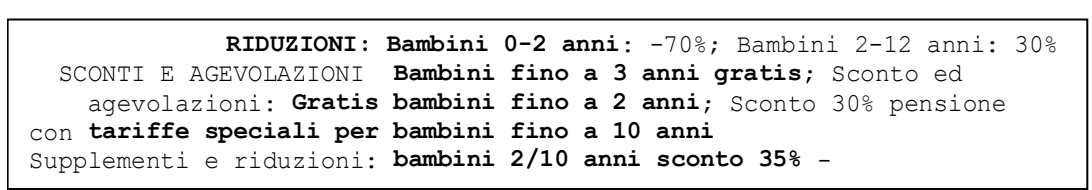

Table 8: bambini + discounts $(25 \%)$

The patterning shown in the citations in Table 8 is very typical. Bambini are never associated with expressions of welcome or expressions denoting an explicit permission to stay in the Agriturismo. However, they regularly (25\%) seem to be connected with the semantic field of discounts, identified by words such as riduzione, sconti e agevolazioni, gratis and gratuito, which, if only implicitly pointing to the welcome, certainly show it in tangible and concrete terms. In Table 7 we reported the only 3 instances of this type in the Farmhols Corpus. In the Agriturist corpus, this is the most typical pattern associated with bambini.

As in the Farmhols Corpus, bambini are associated with some age limitations (fino a 3 anni .., da 2 a 6 anni.., 2/ 10 anni..), but these only refer to the discounts and the reductions offered, and not to the actual acceptance of bambini in the Agriturismo.

To sum up this section, we can say that the contextual analysis of the data in the two languages has shown no match for the word welcome in the context of children. Such mismatch is not only observed for similar grammatical patterns - we had started from the lack of correspondence welcome/benvenuto but also for other lexical or grammatical patterns that might have realised a similar function. In view of this, can we ask ourselves whether this absence of welcome in the Italian of Agriturismo means that children are not really welcomed in Italian Agriturismo, while they are in British farmhouses? We maintain that the analysis should always be extended to the context and the overall function of the unit. So, considering the data we have analysed, perhaps the best answer would be to remind ourselves again of a

TRADTERm, 10, 2004, p. 295-312 
citation from the Farmhols Corpus, where the welcome cannot certainly be taken as encouragement,

'Sorry no Pets No smokers Children over 16 welcomed ...'

and to conclude that the English welcome, when applied to children, may not necessarily convey the warmth and the friendliness that we associate with it: a qualified welcome is perhaps to be interpreted as discouragement to those excluded by the qualification. On the other hand, the fact that no explicit welcome is stated in relation to bambini should also be interpreted in the context of the regular statements about discounts and reductions made available to children, and these should be taken as encouragement for the presence of children in the Italian Agriturismo. It seems to be taken for granted that children are welcome.

\subsection{Pets, dogs and animali}

Pets and dogs are the recipients of the welcome in $20 \%$ of the instances in the Farmhols corpus. In half of these occurrences, however, this welcome is accompanied by a limitation in the offer, as was the case with children. This conditioned welcome is realised here by a variety of expressions ranging from provided, providing, but, to by arrangement and on payment of. We also find some adjectives such as well-controlled and well behaved that also signal a limitation in the welcome:

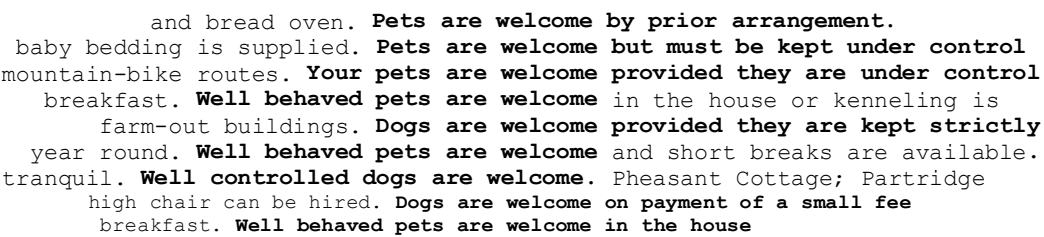

Table 9: pets and dogs + welcome.

TradTerm, 10, 2004, p. 295-312 
These restrictions are perhaps more understandable than the limitations we observed with children because dogs are always perceived as potential dangers on British farms where they often tend to harass sheep or cattle.

Let us now consider the prima-facie equivalent for pets and dogs in the Agriturist corpus. The word pet/s, with its implication of personal closeness and affection, finds no correspondence in Italian and a quick scan at the frequency list from the Agriturist corpus identifies the more general term animali as a potential equivalent. The term animali occurs 65 times in the Italian corpus, but only 23 instances refer to pets rather than to farm animals. Let us consider some citations in Table 10.

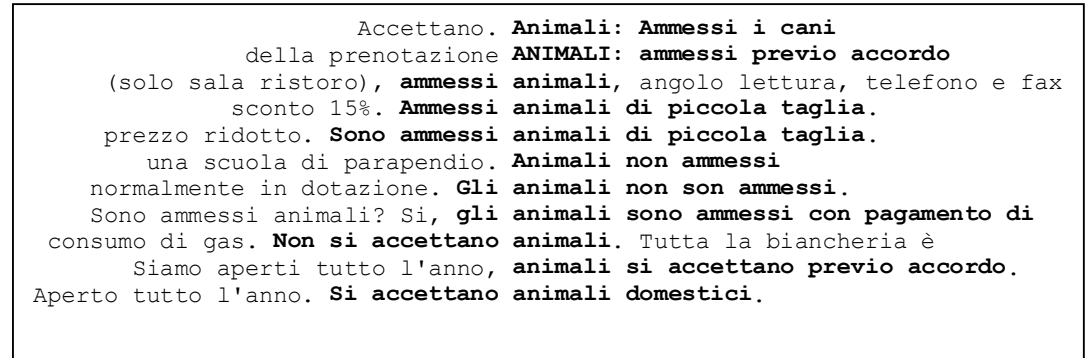

Table 10: Animali + |ammettere/accettare $\mid$.

In the co-text of this word, we notice immediately two possible equivalents to the English welcome: the two verbs |ammettere | and |accettare| in their different inflected forms, always either in the passive, as sono ammessi, or in the impersonal, as si accettano. It is interesting to note that limitations to the presence of animali in the Agriturist corpus exist, although they are perhaps slightly different from the ones we found in the Farmhols corpus. Here, we notice for instance the size, di piccola taglia, which was not mentioned in the English context or the fact that there should be prior agreement, previo accordo, which seems to be more prominent in the Agriturist corpus; in the Farmhols corpus the issue seemed to be more that pets should be well-behaved or kept under control.

From the point of view of the translation equivalence the result is quite satisfactory because, while we could not find a

TradTerm, 10, 2004, p. 295-312 
one-to-one equivalent for welcome in general, we were able to locate a perfectly good equivalent for the English pair welcomepets in the Italian accettare/ammettere-animali. At the level of functionally-complete units of meaning, the pragmatic dimension of the unit is realised by the expressions of limitation associated with it, both in English and in Italian. This suggests that the use of welcome in this context in English is just a euphemism for 'accepted'.

\subsection{Guests, visitors and ospiti}

The patterning associated with welcome in the context of guests and visitors differs from the patterning with children and pets. Here we consistently find the structure $\mid \mathrm{v}-B E+$ welcome + to-inf. | as in Our visitors are welcome to explore the farm ... The concordance in Table 11 groups together some citations for visitors, guests and also the pronoun you which addresses the potential visitor or guest in the text from the web pages.

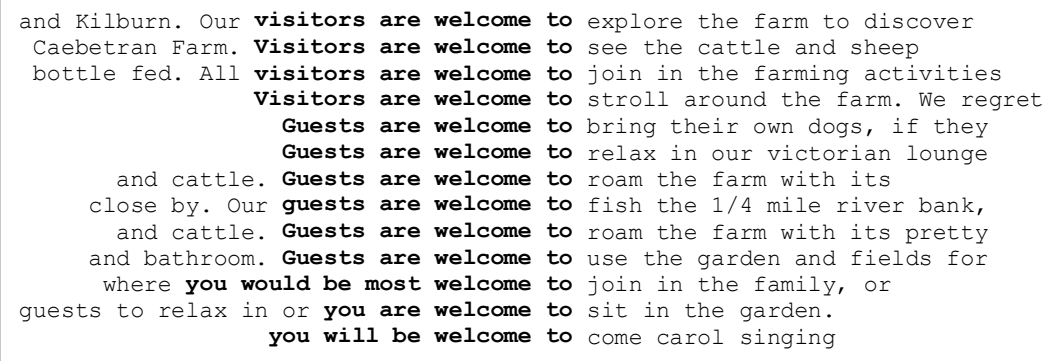

Table 11: Guests/visitors + welcome to.

We note here that this different structure in which welcome is embedded has an impact on the meaning: while with children and pets, the welcome conveyed the meaning of permission and implied that they were allowed to the farmhouse holidays, subject to certain specific conditions; with visitors and guests, we find a straight invitation to take advantage of all the leisurely activities offered by the farmhouse.

TRAdTerm, 10, 2004, p. 295-312 
Let us now consider the Italian equivalent of guests and visitors: ospiti. Again, we note the absence of the typical translation equivalent of welcome as suggested by traditional reference books, i.e. the fully lexical benvenuto/ $i$. Some examples are given in Table 12.

ampi spazi a disposizione degli amici ospiti che potranno raccogliere la forno a legna può essere utilizzato dagli ospiti per attività di svago

può essere raccolta personalmente dagli ospiti, che possono anche assistere di produzione biologica, ove gli ospiti possono raccogliere prodotti Nella fattoria Poggio Oliveto gli ospiti possono visitare le colture

in bicicletta. Esternamente gli ospiti possono godere della piscina, Vi è la possibilità per gli ospiti di partecipare alle attività e nel mese di dicembre $i$ nostri ospiti possono visitare il frantoio er vacanze tranquille e rilassanti. Gli ospiti potranno godere di una piscina ediate vicinanze di Poggio Paradiso gli ospiti potranno fruire di attrezzature

Table 12: Ospiti + |potere |

In the concordance in Table 12, it is pretty clear that the equivalent of the English structure | $\mathrm{Vb}-\mathrm{BE}+$ welcome + to-inf $\mid$ is conveyed in Italian by the modal potere in its inflected forms and also by a lexicalised phrase also related to modality (vi è la possibilità .. di , which carries the same meaning. Here we have the example of a lexical word in L1 that has a grammatical realisation in L2. This is a potential trap for translators because the lexical choice implicitly carries more weight and, as such, may become a more 'visible' and therefore preferred option when translating. We can certainly say that it is the purely lexical meaning that tends to be the focus of traditional reference books. So welcome is translated as benvenuto, and no guidance is given about the likely use of the modal potere. In this case a translation corpus could help us to identify the favourite choices of translators, to verify for instance if the grammatical translation of welcome is indeed used, and if so, if it is used appropriately.

The noun ospiti shows a frequent association with another expression, also related to modality: a disposizione di .. Let us consider some examples in Table 13.

TradTerm, 10, 2004, p. 295-312 
Toscano, 2 piscine a disposizione degli ospiti con una stupenda vista su antico forno a legna a disposizione degli ospiti.

inoltre a disposizione degli ospiti vi sono tre laghetti privati ospiti. A disposizione degli ospiti c'è anche un grande barbecue agriturismo mette a disposizione degli ospiti quattro camere doppie, due

te all'Oppio mette a disposizione degli ospiti tre appartamenti, mentre A disposizione degli ospiti, ampia piscina aperta senese.A disposizione degli ospiti ci sono 3 confortevoli appartamenti

Table 13: Ospiti + a disposizione.

One thing to notice which for lack of space is only mentioned in passing here is the fact that the phrase a disposizione degli ospiti .. in the Agriturist corpus is mainly associated with the type of accommodation offered (e.g. quattro camere doppie), while | welcome + to-inf. | is connected with the different leisure activities offered by the farmhouse holiday package. This points to the specificity of the semantic preference within similar units of meaning and to the fact that collocational restriction is based on semantic criteria. It is certainly something that should be further investigated, especially in view of the impact it can have on the translation process at the level of appropriateness.

\section{The typology of the offer}

The data discussed in the sections above show that, while the single word denoting welcome cannot be translated satisfactorily in Italian, each of the collocational pairs welcome-children, welcome-pets and welcome-guests finds an appropriate translation equivalent (even if this is 0 -equivalence in the case of children) that conveys welcome either in terms of permission or in terms of invitation.

By enlarging the translation unit to encompass the more systematic patterning associated with the initial collocation pair, a typology of the offer specific to each type of guest emerges. We have seen how certain guests (children and pets in the Farmhols corpus, animali in the Agriturist corpus) invited the presence of restrictions while others (bambini and ospiti in the Agriturist corpus, guests in the Farmhols corpus) did not. The type of restrictions we have seen were not the same in the two languages and

TradTerm, 10, 2004, p. 295-312 
310

reflected cultural and ideological preferences: while the presence of children was restricted in terms of age in the Farmhols corpus, in the Agriturist corpus the only qualification was on the type of discount accorded. With pets the restrictions demanded that they should be under control and that they should be well-behaved in the Farmhols corpus, while in the Agriturist corpus the parallel term animali seemed to invite restrictions on size rather than behaviour, and to indicate that specific arrangements for their presence should be made in advance.

The typology of the offer for children included a large safe area, explorer trails, ample space as well as some specific facilities like cots, highchair and child minding. The equivalent offer for bambini in the Agriturist corpus showed predominantly the semantic area of children games and game-parks with words such as giochi per bambini, spazi attrezzati per bambini, piscina rotonda per bambini.

\section{Conclusion}

This paper explored a methodology for translating and comparing meaning across languages that takes the context in which a word is embedded as the primary focus of the translating activity. The traditional distinction between item and environment was reinterpreted here in the belief that a systematic contextual analysis could help to identify a wider type of equivalence where 'functionally-complete units of meaning' are compared across languages. We proposed a method of translation that differs rather radically from the traditional ones. We took as our starting point the recurrent patterns of co-selection of a word and, from them, proceeded to search for an adequate Translation Equivalent (TE).

In practical terms this meant identifying and comparing syntagmatic, that is multi-word, units that shared certain contextual features with a view to identifying a similar function. The problem, of course, is that our conventional notion of translation equivalence does not take into full account the contextual circumstances, usually searching for correspondences at word level. Regarding this point, we showed that if we cannot find a satisfac-

TradTerm, 10, 2004, p. 295-312 
tory one-to-one TE for the adjective welcome, for instance, functional equivalence can be established at the level of the wider units welcome+children, welcome+pets and welcome+guests.

This study has also attempted to show that it must not be taken for granted that the $\mathrm{TE}$ of what appears as a well-formed syntagmatic unit in L1 will be easily retrieved in L2. So, although both welcome and children can be individually translated into Italian, this does not mean that the unit of meaning formed by their combination can be translated.

The methodology we proposed exemplifies a procedure for the comparison of units across languages that goes through a three-stage process: (1) from the original word we aim to translate, to the range of collocates that most characteristically accompanies it; (2) from each collocate to a prima-facie TE in L2; (3) from each $\mathrm{TE}$ to the collocational range that most characteristically accompanies it in L2. This procedure is performed with a view to locating the lexical and grammatical patterns that more characteristically encode the function of our original node word.

Corpus evidence gives us a privileged start by allowing us to examine simultaneously the syntagmatic and paradigmatic dimensions of meaning. We have tried to show that functional equivalence can only be identified by the comparison of possible TEs in the presence of their syntagmatic patterning and their paradigmatic associations in the two languages.

This study has not specifically focused on the typology of the offer in Italian Agriturismo and British farmhouse holidays. However, in the course of our observations, it was apparent that some very interesting insights can be gained from a close look at the data from a typological perspective. In this context, we only want to point to the possibility of identifying the parameters of this offer in a systematic way. We believe that anybody wanting to advertise their offer in a foreign language should be aware of the comparable offer available to their target customers, not only in terms of linguistic realisations but also in terms of the facilities they advertise. This will be the focus of further research in the future.

TradTerm, 10, 2004, p. 295-312 


\section{2}

\section{References}

BAKER, M.; FRANCIS, G. and TOGNINI BONELLI, E. (eds.) (1993) Text and technology: in honour of John Sinclair. Amsterdam and Philadelphia, Benjamins.

BAKER, M. (1993) Corpus linguistics and Translation Studies. Implications and applications. In: Baker, M. et al. above, p. 233-50.

FRANCIS, G. (1993) A corpus-driven approach to grammar. Principles, methods and examples. In: Baker, M. et al. above, p. 137-56.

MANCA, E. (2001) Il linguaggio delle farmhouse holidays e quello dell'agriturismo messi a confronto: realizzazioni linguistiche e tipologia dell'offerta. Tesi di laurea in inglese, Università degli Studi di Lecce.

PARTINGTON, A. (1998) Patterns and meanings. Using corpora for english language research and teaching. Amsterdam and Philadelphia, Benjamins.

SINCLAIR, J. (ed.) (1987) Looking up: an account of the COBUILD project in lexical computing. London, Collins.

SINCLAIR, J. (1987) The Nature of Evidence. In: Sinclair, J. (ed.) above, p. $150-9$.

SINCLAIR, J. (1991) Corpus concordance collocation. Oxford, O.U.P.

SINCLAIR, J. (1996) Corpus to corpus: a study of translation equivalence. In: Sinclair, J. et al. (eds.), p. 171-96.

SINCLAIR, J.; PAYNE, J. and PÉREZ HERNÁNDEZ, C. (eds.) (1996) Corpus to corpus: a study of translation equivalence. International Journal of Lexicography, special issue, 9 (3).

TEUBERT, W. (1996) Comparable or parallel corpora? In: Sinclair, J. et al. (eds.), p. 238-64.

TOGNINI BONELLI, E. (1996a) Towards translation equivalence from a corpus linguistics perspective. In: Sinclair, J. et al. (eds.), p. 197-217.

TOGNINI BONELLI, E. (1996b) Corpus theory and practice. Birmingham, T.W.C.

TOGNINI BONELLI, E. (2001) Corpus linguistics at work. Amsterdam and Philadelphia, Benjamins.

TradTerm, 10, 2004, p. 295-312 